\title{
Formación de sujetos. Reformas, Políticas y Movimientos Sociales
}

DOI: http://dx.doi.org/10.25087/resur3a4

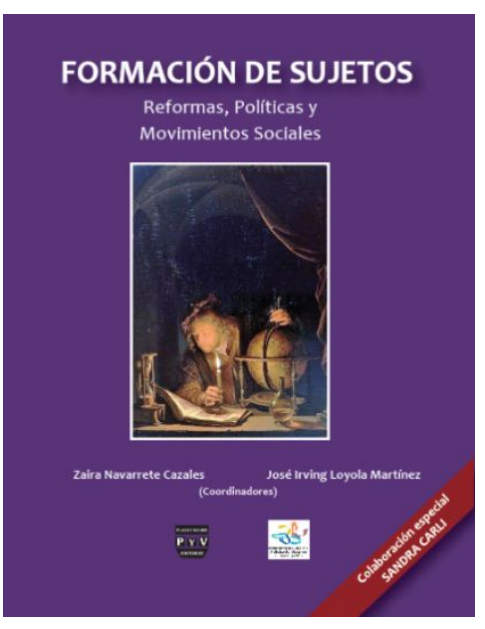

Ariadna Mireya Chávez Hernández ${ }^{1}$

Navarrete Cazales, Zaira y Loyola Martínez José Irving (Coords.) (2016) Formación de sujetos. Reformas, Políticas y Movimientos Sociales, México: Plaza y Valdés / Programa de Análisis Político de Discurso e Investigación, 261 p.

ISBN: 978-607-402-879-9.

El libro: "Formación de sujetos. Reformas, Políticas y Movimientos Sociales" es una valiosa obra que sumerge al lector en una constante e interesante reflexión para entender y estudiar la realidad educativa en vínculo con su realidad político-contextual-educativa. En el libro se realizan una serie de análisis críticos retomando la perspectiva del Análisis Político de Discurso (APD), la cual busca dar cuenta de las maneras en que las estructuras de significación posibilitan formas de conducta ya sean educacionales, políticas, sociológicas, etcétera. A lo largo de la lectura del libro, se irá descubriendo cómo se van generando los discursos políticos que estructuran las actividades de los agentes sociales y qué implicaciones tienen; permite ampliar una visión y contextualización de múltiples factores que entran en juego para la conformación de la educación. El libro está constituido por cuatro rubros temáticos, los cuales abordaré en los siguientes párrafos.

\section{Formación de sujetos: discusiones conceptuales}

${ }^{1}$ Facultad de Filosofía y Letras de la Universidad Nacional Autónoma de México. CE: ariadnachvez@gmail.com 
El capítulo "Lo educativo más allá de la escuela. Experiencia educativa y subjetividad" de Daniel Saur, amplía la concepción de educacional permitirnos visualizar diversos aspectos que entra en juego a la hora de educar entendiendo que toda experiencia, ya sea positiva o negativa, ejerce el efecto de educar al individuo; al mismo tiempo que comprendamos que la problemática de la educación radica en que no existe control de la experiencia, y si toda experiencia educa, el aspecto axiológico de la educación se torna entonces subjetivo en función de la vida, condiciones y experiencias educativas y de vida del sujeto.

El segundo capítulo "Una ontología histórico-discursiva del concepto de formación profesional", de Zaira Navarrete, a partir de un revisión conceptual permite conocer diferentes significados que ha tenido el concepto formación profesional a lo largo de un periodo histórico; nos hace plantearnos la necesidad de abrir horizontes y nuevos enfoques en la educación de una manera holística e incluyente sobre lo que se vive en los espacios externos a la escuela; de manera que coadyuve a crear conocimientos mayormente significativos o lograr una mayor conexión entre la escuela y la vida diaria empleándose estrategias pedagógicas y metodológicas; para, dentro de la realidad externa a la escuela, constituir a los sujetos de manera autónoma.

Finalmente, el tercer capítulo "El significante interculturalidad. Categorías analíticas frente a un breve estado de conocimiento" de Sergio Malaga, nos hace explorar las múltiples concepciones donde se puede enfocar y entender la interculturalidad más allá de las relaciones inter-étnicas, donde me atrevo a mencionar entonces que el ser cognoscente de su realidad o de la percepción de su realidad, está apegado a vivencias, conceptos, experiencias y prototipos socio-culturales en el que vive y en el que está inmerso; mismas que se construyen en función de enfoques de vida, ideologías educativas y políticas, entre otras. De manera que hablar de interculturalidad se volverá complejo y multi exploratorio, la explicación y argumentación de Malaga, ayudará a entender mejor esta realidad.

\section{Reformas y políticas educativas, sociales e institucionales}


El segundo bloque temático está compuesto por 6 capítulos, el primero lo presenta Rosa Nidia Buenfil: "Puntos nodales en la reforma educativa. El artículo III constitucional", la autora explica lo que significa políticamente una reforma constitucional y lo que en la historia mexicana ha implicado. Plantea las tensiones entre particularismo y universalismo presentes en ésta y en cualquier reforma; realiza un análisis acerca de cómo se construye el discurso político sobre leyes educativas constitucionales, permitiéndonos el desarrollo de un análisis abierto sin alguna postura sesgada, intentando prevenir y/o eliminar contradicciones o limitantes que se presentan en el diseño de las reformas educativas.

En el capítulo: "La reforma constitucional a la educación (2013). Aproximaciones al análisis" de Ofelia Cruz, encontraremos cómo se nos sigue disfrazando el verdadero caos educativo, donde por ejemplo, la descentralización de la educación podríamos comprenderla como una centralización a nivel nacional, identificando las políticas educativas como intenciones políticas de control con inclinaciones sesgadas. En el capítulo "Debates y resoluciones del Segundo Congreso Nacional de Instrucción Pública, 1890-1891, en torno a la identidad de la educación media superior", Irving Loyola presenta una cosmovisión de identidad en sujetos, pasando primeramente por una visión analítica histórica donde se aprecia una tendencia globalizante en la educación de evitar para la identidad nacional, todo lo viejo; para mejor incorporar toda aquella noción de modernidad junto con el deseo de emparejarnos con otros países que ya han avanzado, aprendido y determinado en materia de ciencia e industrialización ciertas acciones modernas, mientras que en nuestro país estamos queriendo aprender de esas acciones que pertenecen a una cultura, contexto socio-histórico específico y diferenciado al nuestro.

Posteriormente, el capítulo "La formación de lauderos en México: El caso de la Escuela de Laudería", de Reinalda Soriano, encontraremos un análisis sobre la identidad en los alumnos de la carrera de Laudería en México, donde se analizó la influencia de propuesta curricular a la perspectiva de los estudiantes, reflexionando sobre cómo se ha dejado de lado el papel filosófico y social en la formación de sujetos sociales mencionado por la autora. En el capítulo: "Política educativa y hegemonización de los posgrados dirigidos al 
magisterio en servicio”, María Dolores Ávalos nos habla sobre cómo en este contexto la política educativa se desenvuelve de una manera dominante y de imposición mediante relaciones verticales procreadoras de significantes vacíos; y finalmente encontraremos el capítulo de María Joaquina Sánchez titulado: "Planeación nacional ambiental en el contexto del gobierno de Enrique Peña Nieto" donde nos ayudará a visualizar cómo esta planeación no obedece verdaderamente a las necesidades sociales ni problemas eco-sociales en las que nos encontramos como país, sino más bien es un programa simulador que obedece un paradigma de conveniencia global-capitalista.

\section{Movimientos Sociales}

Este tercer rubro temático inicia con el capítulo: "Traspasos y desencuentros discursivos en la construcción narrativa de los movimientos estudiantiles en México (1960-1980)” de Mónica García, donde identifica y discute traspasos discursivos entre la historia constituida a partir de narrativas hegemónicas sobre los movimientos estudiantiles en México y memorias narrativizadas de mujeres activistas. En el capítulo: "El debate por la autonomía. Una aproximación a la dimensión política de la universidad", Leonor Gonzáles nos permite vislumbrar en el análisis sobre el concepto de autonomía junto con su traducción, influencia y aplicación en la universidad como eje de articulación y diferencias para con la Universidad; mismo análisis que posicionará a la universidad en otro nivel y enfoque para el analista profesional, así como para quienes no se dedican al análisis de manera profesional.

\section{Comentarios y críticas a la perspectiva del Análisis Político de Discurso}

En el cuarto rubro temático encontramos una integración y análisis mayor sobre los capítulos principales de este libro: I Formación de sujetos: Discusiones conceptuales, y II Reformas y políticas educativas, sociales e institucionales. De manera que con los trabajos de Ignacio Pineda, Arturo Torres, María Evangelina Palomar, y María de los Ángeles de la Rosa, podremos integrar y conceptualizar mejor: la realidad de subjetividad que se mantiene en procesos de constitución de sujetos educativo con el trabajo de Pineda. 
Posteriormente gracias a un análisis entre el APD y la tradición hermenéutica, Torres nos hará entender que los principios teóricos y criterios metodológicos vienen de la tradición de la filosofía Hermenéutica y de la propuesta "deconstructiva" desarrollada por Jacques Derrida. Luego, con Palomar, encontraremos cómo para las reformas educativas, leyes y cambios docentes o legales en materia de educación, los significantes vacíos, están sumergidos o constituidos de significados subjetivos o de controversia, con los cuales se ejerce el poder y se negocia entre otras importantes reflexiones. Se toma así conciencia de cuánto es imposición y cuánto es un acto de atención a las necesidades locales. Para el final de este capítulo nos encontraremos con la amplia concepción en que puede ser entendida y en que debe ser estudiada la diversidad y la interculturalidad, conceptos que pueden implicar posicionamientos políticos concretos según de la Rosa, por lo que será de vital importancia leer con detenimiento cada tema tratado en este capítulo.

\section{Invitada especial}

Finalmente, en el quinto rubro de este libro disfrutaremos de un ensayo-análisis inédito a cargo de la autora Sandra Carli, quien ha sido invitada especial para este valioso libro. La autora señala que en el año 2008 se cumplió el 90a aniversario de la Reforma Universitaria de 1918. Ese acontecimiento histórico debe ser considerado teniendo en cuenta sus particularidades, el contexto mundial, nacional y local en el que surge, pero también la cadena de filiación que inaugura en torno a la problemática de la relación entre universidad, sociedad y política. La autora nos adentrará de manera dinámica e interesante a dimensionar, reflexionar y cuestionar sobre: ¿una auténtica república democrática en la Universidad Argentina y en nuestras universidades latinas?; conceptos como el canon épico-político, selectividad invisible, entre otros, que nos harán reflexionar sobre los verdaderos problemas políticos de la universidad; así como el analizar a la universidad como una posible comunidad de consumidores que funciona como reclutadora y formadora de las clases medias -como comenta la autora-; así como el ayudarnos a reflexionar sobre el cambio del sentido de comunidad de universidad a nivel mundial; así como el análisis del 
enfoque de la revolución de las conciencias universitarias hoy en día, mismo que nos hará entender que éstas conciencias revolucionarias están manipuladas y controladas por un discurso ideo-político hegemónico, en lugar de realizar una crítica activa acerca de la resolución de los problemas específicos de la vida universitaria actual.

Ante todo lo expuesto, podemos asegurar al lector que la lectura y análisis de este libro, será de gran satisfacción e interés para el que desee ampliar su cosmovisión de las realidades de la educación junto con todo lo que influye y engloba la formación de los sujetos junto con todos los actores e instituciones implícitas en ello para dimensionar la importancia del todo que en este conjunto implica para la educación de todo tipo, hacia la realidad política, histórica, social y eco-social. Esto con intención de seguir encontrando una observación integral de la realidad con idea de encontrar pautas, temas y puntos imprescindibles de revisión para mejorar la manera de abordar el análisis de la educación; y quizá hasta para intentar cambiar alguna realidad en nuestra educación y de acuerdo a nuestras posibilidades objetivas.

\section{Referencia}

Navarrete-Cazales, Z. y Loyola-Martínez, J. I. (Coords.) (2016) Formación de sujetos. Reformas, Políticas y Movimientos Sociales, México: Plaza y Valdés / Programa de Análisis Político de Discurso e Investigación, 261 p. 